\title{
Pastoralist-predator interaction at the roof of the world: Conflict dynamics and implications for conservation
}

\author{
$\underline{\text { Jaffar Ud Din }}^{1,2}, \underline{\text { Hussain Ali }}^{1,3}, \underline{\text { Aziz Ali }}^{4}, \underline{\text { Muhammad Younus }}^{1}, \underline{\text { Tahir Mehmood }}^{5}$, Yusoff Norma-Rashid $^{2}$ and Muhammad Ali $^{1,3}$ \\ Nawaz $^{1,3}$
}

\begin{abstract}
Pastoralism and predation are two major concomitantly known facts and matters of concern for conservation biologists worldwide. Pastoralist-predator conflict constitutes a major social-ecological concern in the Pamir mountain range encompassing Afghanistan, Pakistan, and Tajikistan, and affects community attitudes and tolerance toward carnivores. Very few studies have been conducted to understand the dynamics of livestock predation by large carnivores like snow leopards (Panthera uncia) and wolves (Canis lupus), owing to the region's remoteness and inaccessibility. This study attempts to assess the intensity of livestock predation (and resulting perceptions) by snow leopards and wolves across the Afghani, Pakistani, and Tajik Pamir range during the period January 2008-June 2012. The study found that livestock mortality due to disease is the most serious threat to livestock (an average 3.5 animal heads per household per year) and ultimately to the rural economy (an average of US\$352 per household per year) as compared to predation (1.78 animal heads per household per year, US\$191) in the three study sites. Overall, 1419 (315 per year) heads of livestock were reportedly killed by snow leopards $(47 \%)$ and wolves $(53 \%)$ in the study sites. People with comparatively smaller landholdings and limited earning options, other than livestock rearing, expressed negative attitudes toward both wolves and snow leopards and vice versa. Education was found to be an effective solution to dilute people's hatred for predators. Low public tolerance of the wolf and snow leopard in general explained the magnitude of the threat facing predators in the Pamirs. This will likely continue unless tangible and informed conservation measures like disease control and predation compensation programs are taken among others.
\end{abstract}

Key Words: Afghan Pamir; carnivore; conflict; Pak Pamir; pastoralist; predation; snow leopard; Tajik Pamir; wolf

\section{INTRODUCTION}

Large carnivores like big felids and canids have a profound impact on biological communities. They alter the structure and function of entire ecosystems by regulating or limiting the number of prey species (Schaller 1976, Estes et al. 1998, Berger et al. 2001, Terborgh et al. 2001). They are also considered flagship species because their presence often benefits other life forms (Linnell et al. 2000). Biologists are therefore interested in their conservation and management (Nowell and Jackson 1996, Treves and Karanth 2003). However, carnivore conservation efforts are often hindered by conflict with humans (Nowell and Jackson 1996). Humans are generally tolerant to wildlife species where an economic return is involved, as the case with ungulates, but exhibit negative attitudes toward predators, especially where pastoralism is involved (Woodroffe 2000). Human resentment of carnivores is directly linked with livestock predation (Thirgood et al. 2000). Other phenomena explaining human-carnivore conflict include the competition of carnivores with humans for the consumption of wild ungulates (Treves and Karanth 2003) and even attacks on human themselves (Oli et al. 1994, Mishra et al. 2003, Löe and Röskaft 2004). Rapid increase in human population has also resulted in humans encroaching on landscapes used by carnivores (Fox and Tsering 2005, Tsering et al. 2006, Rosen et al. 2012). Better-managed protected areas are considered safe havens for carnivores, but have caused an increase in human-carnivore conflict in buffer zones (Tsering et al. 2006). Livestock herding is generally within the ambit of poor nomads in south and central Asia (Naughton-Treves 1998, Kreutzmann 2003, Pratt et al. 2004,
Linkie et al. 2007, Mock et al. 2007). It is the only means of livelihood for transhumance families. Carnivores can inflict heavy economic losses in such cases (Mishra 1997, Bagchi and Mishra 2004). Annual livestock loss accounts for $2-5 \%$ of total herd size in some areas (Mallon 1984, Fox et al. 1991, Oli et al. 1994, Mishra 1997). This is significant, i.e., US\$128-190 per family, much as it is in trans-Himalayan India, south and central Asia (Mishra 1997, Namgail et al. 2007), Pakistan (Hussain 2003, Dar et al. 2009, Din et al. 2013), and Afghanistan (Mishra and Fitzherbert 2004, Mock et al. 2007). Studies show that livestock constitutes $40-70 \%$ of carnivore diet in India and Pakistan (Bagchi and Mishra 2004, Anwar et al. 2011). Consequently, agro-pastoralist communities retaliate by directly killing carnivores, opposing wildlife sanctuaries close to farms, or by resisting the reintroduction of extirpated predators into their former ranges (Graham et al. 2005). This makes carnivore conservation a challenging task for conservationists' worldwide (Bangs et al. 1998, Karanth and Madhusudan 2002; Berg 1998, unpublished manuscript). Despite these challenges, conservationists are trying to help pastoralist communities through various incentives programs (Din et al. 2013). Though these efforts are helpful in altering human perceptions about carnivores (Bagchi and Mishra 2004), they are not substantial enough when compared with the economic loss sustained by pastoralists due to predation (Mishra et al. 2003) on livestock.

A poor understanding of the social-ecological factors responsible for human-carnivore conflict further exacerbates the issue (Bagchi and Mishra 2004). Such judgment becomes

\footnotetext{
${ }^{1}$ Snow Leopard Trust, Islamabad, Pakistan, ${ }^{2}$ Institute of Biological Sciences, Faculty of Science, University of Malaya, Kuala Lumpur, Malaysia, ${ }^{3}$ Department of Animal Sciences, Quaid-i-Azam University, Islamabad, Pakistan, ${ }^{4}$ Agha Khan Foundation (AKF) National Program Office, Kabul, Afghanistan, ${ }^{5}$ Biostatistics, Department of Chemistry, Biotechnology and Food Sciences, Norwegian University of Life Sciences, Norway
} 
Fig. 1. Map of the Pamirs showing data collection sites.

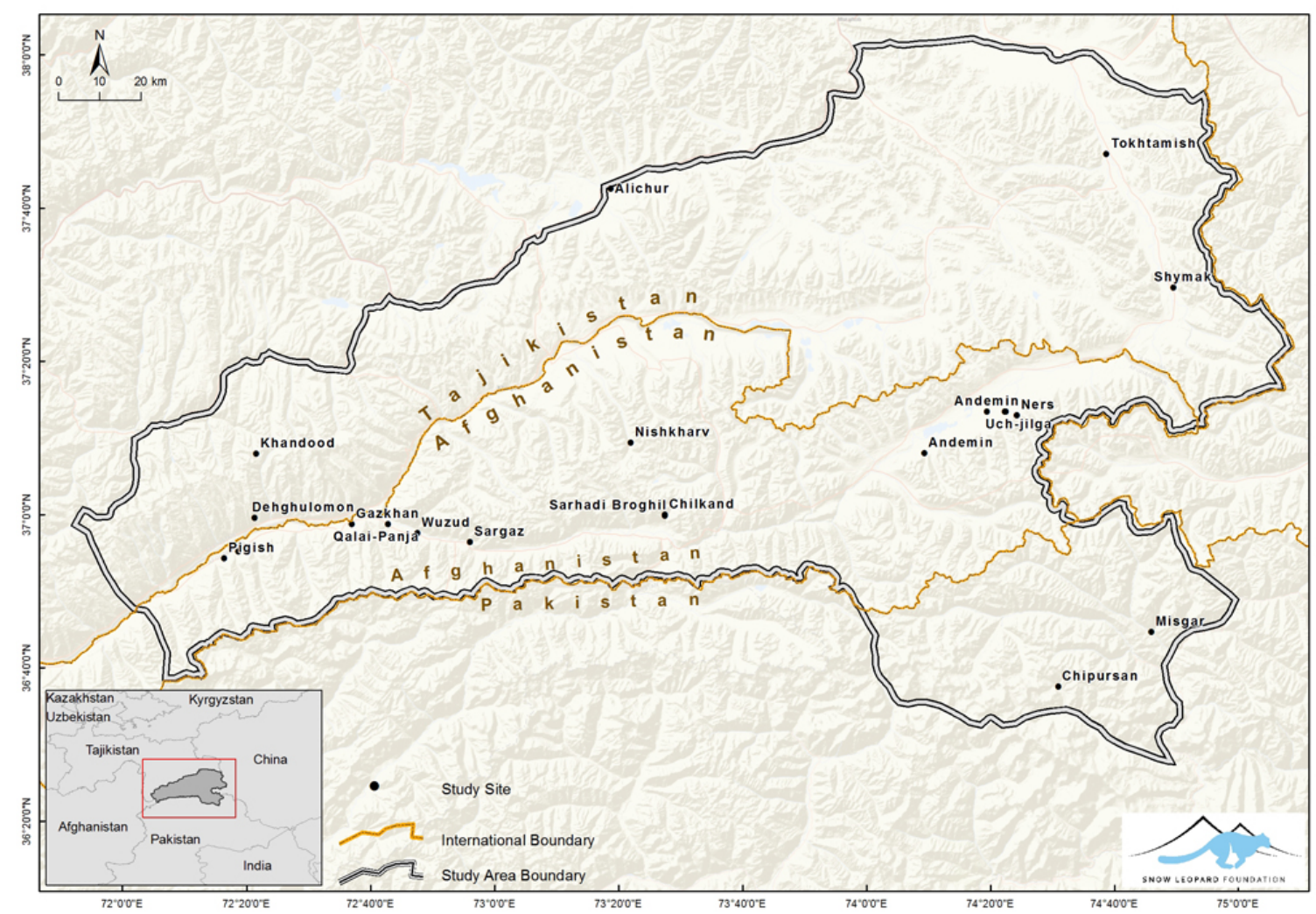

institutionalized in unique and social-ecologically secluded, but rich biodiversity corridors like the Pamir mountain range.

The Pamir mountain range is listed among the world's 200 ecoregion list (Olson et al. 2001) and considered a biodiversity hotspot because of its exceptional geographic position coupled with socio-cultural (Kreutzmann 2003) and ecological diversity (Xie et al. 2007). Efforts are underway for the establishment of a transboundary Peace Park covering the Afghan, Chinese, Pakistani, and Tajik Pamirs, primarily for the conservation of flagship species such as the snow leopard (Panthera uncia) and Marco Polo sheep (Ovis ammon polii; Olson et al. 2001). Other major predators presumed to be distributed across the Pamirs include the grey wolf (Canis lupus), brown bear (Ursus arctos), and Himalayan lynx (Lynx lynx isabellinus). The agro-pastoralist communities of the Pamirs have been dwelling in these remote mountains alongside threatened wildlife for centuries. However, knowledge about the coexistence of humans and carnivores in the Pamirs remains rudimentary; such information is vital for formulating long-term scientific conservation management practices. Available literature (Schaller 1998, Hurni and Breu 2003, Mishra and Fitzherbert 2004, Din et al. 2013) describes the severity of human-carnivore conflict in various regions of the Pamirs and suggests that range countries explore and update information on indigenous wildlife (Xie et al. 2007).

Human attitudes and perceptions about large carnivores constitute one of the key parameters of human-carnivore conflict (Røskaft et al. 2007) and are considered among the decisive factors in formulating conservation management strategies (Wechselberger and Leizinger 2005). We attempt to estimate the economic value of livestock belonging to pastoralist communities in the periphery of the Pamir Knot-the meeting point of the Afghanistan, Pakistan, and Tajikistan Pamirs-and their perceptions, attitudes, and tolerance of snow leopards and wolves in light of livestock losses to predation. To find out how relevant the predation-induced loss is, as compared with other types of livestock losses, we also evaluated disease-caused mortality of livestock and associated economic liability and compared the significance of each to the region's overall economy.

\section{METHODS}

\section{Study area}

The study area encompassed the Afghan Pamirs (the valleys of the lower and upper Wakhan corridor), the Tajik Pamirs (the valleys of Tokhtamish, Shymak, and Alichiur), and the Pakistan Pamirs (the valleys of Misgar and Chipursan; Fig. 1). Flanked by the Hindu Kush, Himalayas, Karakoram, and Kunlun mountains, the Pamirs forms one of the most stunning mountain ranges in the world and are known as the "roof of the world" (Bliss 2005). The Pamirs are bounded by Kashgar and the Tarim Basin in the east, the Trans-Alai Mountains in the north, the Hindu Kush in the south, and a complex set of physiographic features that correspond to $73^{\circ} \mathrm{E}$ longitude to the west (Olson et al. 2001). The Pamirians represent two major language groups, Iranian and Turkic, of this part of central Asia. Wakhi is a branch of the eastern Iranian languages within the Indo-Iranian group 
while Kirghiz is a Turkic language belonging to the Altaic group (Kreutzmann 2003). The Pamir's grasslands and semideserts act as a major biogeographic barrier between Mediterraneaninfluenced middle Asia, monsoonal South Asia, and the continental expanses of central Asia (Olson et al. 2001).

The alpine climate produces extremes in which average summer and winter temperatures range from $23^{\circ} \mathrm{C}$ to $-18^{\circ} \mathrm{C}$ with seasonal and annual precipitation ranging from $50 \mathrm{~mm}$ to $300 \mathrm{~mm}$ (Xie et al. 2007). The specific attraction of this altitudinal ecological belt is the availability of water stored in glaciers and snow that feeds irrigation systems. Though the Wakhi grow crops, the Kirghiz have traditionally refrained from any form of settled agriculture. Both groups utilize high pastures where groundwater and runoff create seasonal meadows (Kreutzmann 2003).

The Pamirs are unique because of their rich socio-cultural heritage and identified by WWF as the "Pamir alpine desert and tundra" (Olson et al. 2001). The mammalian fauna of the Pamirs include iconic species like the Marco Polo sheep and endemic species such as the Himalayan ibex (Capra sibirica), blue sheep (Pseudois nayaur), Ladakh urial (Ovis orientalis), snow leopard, grey wolf, and brown bear.

\section{Data collection}

We used pretested (Din and Nawaz 2010, Din et al. 2013) structured questionnaires covering important conflict-inducing parameters such as study site demographic features, pastoralism practices and herd dynamics, status of large carnivores, predation intensity patterns and associated economic losses, and human perceptions, attitudes, and tolerance of predators (Appendix 1). Experienced research staff from the Snow Leopard Foundation (SLF) collected data from the Pakistan Pamirs while Aga Khan Foundation (AKF) field staff facilitated the process in the Afghan and Tajik Pamirs. Study partners stayed in touch during the data collection and decoding period to maintain standards and homogeneity. Informants included herders, farmers, wildlife guards, students, and teachers. One adult, usually the head of the household, was interviewed and we reached a minimum of $10 \%$ of households in each village. Survey objectives were explicitly communicated prior to survey initiation to check respondent expectations and avoid embellished information. Predation incidences reported during the period January 2008-June 2012 were recorded.

\section{Documenting livestock based economy}

We grouped informants' livestock types into four categories, namely sheep, goat, cattle (bull, cow, and calf), and other (yak and equine). We calculated communities' economic return (marketing animals or consuming domestically) using the average price per animal in local markets with the total number of animals utilized. We also tested the variation in economic impact per household per year in each study site, statistically.

\section{Estimating livestock losses}

Livestock predation incidences were assessed very carefully. We recorded only those where informants were able to identify predators directly (predator sighted on the spot or previously near the predation spot). Indirect identification was restricted to signs left by predators or that the kill reflects the predation instinct of a particular predator (Namgail et al. 2007, Din et al. 2013). Furthermore, we filtered herders', who generally differentiate between snow leopard and wolf kills based on carcasses, reports and did not include instances where herders were unable to recall the number, age, sex, and chronological evidences related the livestock killed.

We also counted livestock losses due to disease, compared them with losses to predation, and evaluated the economic loss associated with each type.

\section{Data analysis}

We used parametric and nonparametric tests to evaluate and summarize variation among different factors in the statistical analysis software, R (R Development Core Team 2015). We run lasso logistic regression in R using package "glmnet" (Friedman et al. 2010) to test the influence of social and demographic factors on human attitude toward large carnivores.

The public perception about carnivores, gauged through the question if they want to increase or maintain population of snow leopard or wolf (yes $=1$ or no $=0$ ), was used as response variable, upon which effects of several factors, including education, income, occupation, land holding, type and number of livestock, valleys, countries, year, season, prey sex, age, and predation time were tested through logistic regression by,

$$
\begin{aligned}
& \log \frac{p(\text { Public Perception })}{1+p(\text { Public Perception })} \\
&\left.=\beta_{0}+\beta_{1}(\text { Education })+\beta_{2}(\text { Income })+\beta_{3} \text { (Occupation }\right) \\
&+\beta_{4}(\text { Land holding })+\beta_{5}(\text { Number of livestock }) \\
&+\beta_{6}(\text { Valley })+\beta_{7}(\text { Country })+\beta_{8}(\text { Season }) \\
&+\beta_{9}(\text { Prey sex })+\beta_{10}(\text { Prey age }) \\
&\left.+\beta_{11} \text { (Predation time }\right)+ \text { Residuals }
\end{aligned}
$$

The logistic regression coefficients present the change in log odds ratios with per unit change in respective factor. The logistic regression assumes the explanatory factors to be linear and to address the potential risks of multicollinearity, we added lasso penalty (Tibshirani 1996, Chen et al. 1998) to the logistic regression (Tong et al. 2009), i.e.,

$$
\lambda \sum_{j=1}^{10}\left|\beta_{j}\right| \rightarrow 0
$$

The lasso penalty removes week factors from the regression model through tuning constant $\lambda$ (lambda), which shrinks the logistic regression coefficients $(\beta)$ toward the zero. The tuning constant was tuned through 10 -fold cross-validation in simpler settings to find the best value of $\lambda$. The testing classification error for each test set was computed from the training set. A range of values of $\lambda$ were used to determine its minimum. The percentage of correctly identified samples was used to quantify model performance. We first split the data into two sets randomly in the ratio of 0.7 . The largest set that takes $70 \%$ of the samples was used to train the model. Test data was used to assess model performance once the optimum model was selected. We ran separate models for each snow leopard and wolf.

\section{RESULTS}

\section{Social structure and livelihood system}

We contacted a total of 182 informants (average 60.7 informants per country) in the Afghan Pamirs, Pakistani Pamirs, and Tajik Pamirs. Average household size was $6.8(\mathrm{SE}=0.7)$ while average 
Table 1. Livestock holding, local consumption, and economic valuation of livestock owned by the respondents

\begin{tabular}{|c|c|c|c|}
\hline & Afghan Pamir & Pakistan Pamir & Tajik Pamir \\
\hline Number of respondents & 42 & 100 & 40 \\
\hline Total livestock owned & 3498 & 2899 & 3671 \\
\hline Average herd size & 83 & 29 & 55 \\
\hline Total animals consumed locally per year & 169 & 185 & 175 \\
\hline Consumption per household per year & 4 & 2 & 4 \\
\hline Total animals marketed per year & 963 & 393 & 475 \\
\hline Animals marketed per household per year & 23 & 4 & 12 \\
\hline Total income generated in US\$ & 76,105 & 45,943 & 65,729 \\
\hline Economic impact per household in US\$ & 1812 & 459 & 1643 \\
\hline
\end{tabular}

respondent age was 45 years $(\mathrm{SE}=2.5)$. The difference in household size using Kruskal-Wallis $(\mathrm{KW})$ test $(\mathrm{H}=2.0, \mathrm{DF}=$ $2, \mathrm{p}>0.05)$ and age groups $(\mathrm{H}=2.0, \mathrm{DF}=2, \mathrm{p}>0.05)$ across the three study sites was not significant. Herders constituted $40 \%$ of total respondents, farmers $23 \%$, the general public $20 \%$, wildlife guards $10 \%$, and students/teachers $6 \%$. Earning members per household ranged from 0 to 7 (mean $=3.8)$ while landholding per household varied from 0.05 to 3.8 hectares $($ mean $=1.9$ hectare). The majority of respondents had attended high school $(42 \%)$, followed by the categories of illiterate $(28 \%)$, college educated $(18 \%)$, and those having basic education $(12 \%)$. The literacy rate was the highest in the Tajik Pamirs (100\%), followed by the Pakistani Pamirs (73\%), and the Afghan Pamirs (43\%).

Informants reported holding some 10,068 animals in total (Table $1)$, with sheep constituting $55 \%(n=5526)$, goats $27 \%(n=2,672)$, cattle $16 \%(n=1,630)$, and other $2 \%(n=241)$. Average herd size per household did not vary significantly among the three countries $(\mathrm{H}=2, \mathrm{DF}=2, \mathrm{p}>0.05)$. Annual average livestock culling for domestic purposes was higher in the Tajik and Afghan Pamirs (4 animals) as compared to the Pakistani Pamirs (2 animals). Similarly, 1831 animals $($ mean $=610)$ were marketed in one year (Table 1) with resulting revenues of US\$187,777 (mean $=$ US\$62,592).

\section{Livestock losses}

We found snow leopards and wolves to be the major causes of human-carnivore conflict in the Pamirs. Livestock losses to brown bear and lynx were very rare $(<1 \%)$.

Overall, 1419 (315 per year and 1.7 per household per year) livestock were reportedly killed by snow leopards $(47 \%)$ and wolves $(53 \%)$ in the three study sites during the study period. Predation losses due to snow leopards were recorded as highest at $76 \%$ in the Pakistani Pamirs and 24\% in the Afghan Pamirs. There were no reports of snow leopard predation from the Tajik Pamirs (Table 2). Wolf-induced mortality of livestock was the highest in the Afghan Pamirs (49\%), followed by the Pakistani Pamirs (37\%), and the Tajik Pamirs (14\%). Mean mortality of livestock types induced by wolf varied significantly $(\mathrm{F}=3.8, \mathrm{P}=$ 0.03 ) across the study sites while snow leopard predation cases $\operatorname{did} \operatorname{not}(\mathrm{F}=1.4, \mathrm{p}>0.05)$.

A total of 2868 animals (637 per year) reportedly died in the Pamirs because of diseases during the study period of 4.5 years. Livestock losses per household per year were the highest in the Afghan Pamirs (7.0), followed by the Pakistani (2.7), and Tajik Pamirs (1.8). Sheep were found to be more susceptible to disease
$(45.3 \%)$ than goats $(44.4 \%)$, cattle $(10 \%)$, and others $(0.4 \%)$. Average per-household loss (all study sites) estimated at 3.5 animals is considerably greater than the corresponding loss to predation (1.7 animals).

\section{Economic value of livestock losses}

Predation and diseases together constituted an economic loss of US\$445,539 (US\$99,009 per year) in the entire study area during the study period (Table 3 ). Predation-caused economic losses were estimated at US\$156,654 (35\%) whereas disease-caused losses accounted for US\$288,885 (65\%). Snow leopard-caused economic loss per year was estimated at US\$14,801 (43\%) whereas the figure for wolves was US\$20,011 (57\%). Predation-induced losses per household per year were the highest in the Afghan Pamirs (US\$241), followed by the Pakistani (US\$202), and Tajik Pamirs (US\$113). The average loss per household across the three sites was US\$191 (Table 4). Similarly, disease-caused economic loss per household per year was the highest in the Afghan Pamirs (US\$593) as compared with the Pakistani (US\$295) and Tajik Pamirs (US\$245). The average was US\$353. Disease-induced livestock losses had been expected to affect the household economy more than predation-induced losses, but the mean economic loss due to either category did not vary much $(\mathrm{H}=2$, $\mathrm{DF}=2, \mathrm{p}>0.05)$.

\section{Human attitudes toward predators}

Nearly all respondents in Tajik Pamir, 95\% in Afghan Pamir, and $90 \%$ in Pak Pamir considered wolf as more lethal to livestock than snow leopard. Consequently, $85 \%$ and $53 \%$ of respondents were in favor of reduced wolf and snow leopard populations, respectively. All the participants from Tajik and Afghan Pamir were found to have negative attitudes toward wolf, whereas only $28 \%$ of the respondents from Pak Pamir were in favor of maintaining wolf populations. Public tolerance for snow leopards was comparatively better in the Tajik Pamirs where $82.5 \%$ of respondents were in favor of maintaining populations. Public tolerance of snow leopards in the Afghan and Pakistani Pamirs were $48 \%$ and $32 \%$, respectively.

Education, number of earning family members, and family landholding were found to be good indicators of people's attitudes toward the snow leopard. For instance, teachers were in favor of preserving snow leopards 2.29 times more than people in other occupations. Similarly, an increase in the number of earning family members' per household, and increases in family landholding resulted in a 1.01 times (each) more positive attitude toward snow leopards. Furthermore, respondents who did spot 
Table 2. Livestock losses due to predators and diseases in the Pamirs during the period January 2008-June 2012.

\begin{tabular}{|c|c|c|c|c|c|c|c|c|c|c|c|c|}
\hline & \multicolumn{4}{|c|}{ Afghan Pamirs } & \multicolumn{4}{|c|}{ Pakistani Pamirs } & \multicolumn{4}{|c|}{ Tajik Pamirs } \\
\hline & $\begin{array}{c}\text { Total } \\
\text { livestock }\end{array}$ & $\begin{array}{r}\text { Total } \\
\text { killed }\end{array}$ & $\begin{array}{c}\% \\
\text { killed }\end{array}$ & $\begin{array}{c}\text { Losses per } \\
\mathrm{HH}\end{array}$ & $\begin{array}{c}\text { Total } \\
\text { livestock }\end{array}$ & $\begin{array}{r}\text { Total } \\
\text { killed }\end{array}$ & $\begin{array}{c}\% \\
\text { killed } \\
\end{array}$ & $\begin{array}{c}\text { Losses per } \\
\mathrm{HH}\end{array}$ & $\begin{array}{c}\text { Total } \\
\text { livestock }\end{array}$ & $\begin{array}{r}\text { Total } \\
\text { killed }\end{array}$ & $\begin{array}{c}\% \\
\text { killed } \\
\end{array}$ & $\begin{array}{c}\text { Losses per } \\
\mathrm{HH}\end{array}$ \\
\hline \multicolumn{13}{|l|}{ Livestock } \\
\hline Goat & 598 & 169 & 32.1 & 0.89 & 1490 & 450 & 57 & 1.00 & 584 & 15 & 15 & 0.08 \\
\hline Sheep & 2105 & 330 & 62.6 & 1.75 & 1062 & 273 & 35 & 0.61 & 2359 & 66 & 65 & 0.37 \\
\hline Cattle & 634 & 2 & 0.4 & 0.01 & 282 & 32 & 4 & 0.07 & 714 & 2 & 2 & 0.01 \\
\hline Other & 161 & 26 & 4.9 & 0.14 & 65 & 35 & 4 & 0.08 & 15 & 19 & 19 & 0.11 \\
\hline Total & 3498 & 527 & 100 & 2.79 & 2899 & 790 & 100 & 1.76 & 3672 & 102 & 100 & 0.57 \\
\hline \multicolumn{13}{|l|}{ Predator $^{\dagger}$} \\
\hline Snow leopard & & 160 & 30.4 & 0.87 & & 513 & 64.94 & 1.14 & & 0 & 0 & 0 \\
\hline Wolf & & 367 & 69.6 & 1.99 & & 277 & 35.06 & 0.62 & & 102 & 100 & 0.57 \\
\hline Total & & 527 & 100 & 2.79 & & 790 & 100 & 1.76 & & 102 & 100 & 0.57 \\
\hline Disease $^{*}$ & & 1316 & 38 & 6.96 & & 1232 & 42.5 & 2.74 & & 320 & 9 & 1.78 \\
\hline
\end{tabular}

$\dagger$ Percentage of total livestock predation by snow leopard and wolf;

\$Percentage of total livestock killed by the disease.

Table 3. Annual monetary losses (US\$) incurred by Pamirians due to livestock depredation by predators and diseases.

\begin{tabular}{|c|c|c|c|c|c|c|c|c|}
\hline & \multicolumn{2}{|c|}{ Afghan Pamir } & \multicolumn{2}{|c|}{ Pakistan Pamir } & \multicolumn{2}{|c|}{ Tajik Pamir } & \multicolumn{2}{|c|}{ Total } \\
\hline & Predation & Disease & Predation & Disease & Predation & Disease & Predation & Disease \\
\hline Goat & 5915 & 15,470 & 42,750 & 69,445 & 1560 & 10,400 & 50,225 & 95,315 \\
\hline Sheep & 23,100 & 49,000 & 20,748 & 31,236 & 8,250 & 23,375 & 52,098 & 103,611 \\
\hline Cattle & 526 & 44,447 & 10,656 & 28,305 & 626 & 10,329 & 11,808 & 83,081 \\
\hline Other & 15,964 & 3,070 & 16,660 & 3808 & 9899 & - & 42,523 & 6878 \\
\hline Total & 45,505 & 111,987 & 90,814 & 132,794 & 20,335 & 44,104 & 156,654 & 288,885 \\
\hline Loss per year & 10,112 & 24,886 & 20,181 & 29,510 & 4519 & 9801 & 89,208 & 64,197 \\
\hline Loss per household & 241 & 593 & 202 & 295 & 113 & 245 & 191 & 353 \\
\hline
\end{tabular}

Table 4. Predator specific monetary losses (US\$) incurred by respondents in the study sites.

\begin{tabular}{lcccccc}
\hline \hline & Goat & Sheep & Cattle & Other & Total & Loss/ year \\
\hline Snow Leopard & 29,500 & 21,422 & 7992 & 7692 & 66,606 & 14,801 \\
Wolf & 20,725 & 30,676 & 3816 & 34,831 & 90,048 & 20,011 \\
Total & 50,225 & 52,098 & 11,808 & 42,523 & 156,654 & 34,812 \\
\hline
\end{tabular}

Table 5. Factors affecting attitudes toward snow leopards (Panthera uncia) and wolves (Canis lupus) in the study sites. (Parameters are estimated by lasso regression model.)

\begin{tabular}{|c|c|c|c|c|c|c|}
\hline & Intercept & $\begin{array}{l}\text { Occupation: } \\
\text { Teacher }\end{array}$ & Earning members & Landholding & $\begin{array}{c}\text { Snow leopard } \\
\text { sighted }\end{array}$ & $\begin{array}{c}\text { Education: } \\
\text { Illiterate }\end{array}$ \\
\hline \multicolumn{7}{|l|}{ Snow leopard } \\
\hline Coefficient & -1.055 & 0.83 & 0.009 & 0.01 & -0.031 & - \\
\hline Odds Ratio & 0.348 & 2.293 & 1.01 & 1.01 & 0.961 & - \\
\hline SE & 0.53 & 0.618 & 0.165 & 0.026 & 0.116 & - \\
\hline p-value & $<0.000$ & 0.016 & 0.043 & 0.046 & 0.023 & - \\
\hline \multicolumn{7}{|l|}{ Wolf } \\
\hline Coefficient & -2.214 & 0.651 & 0.299 & 0.045 & - & -1.213 \\
\hline Odds Ratio & 0.109 & 1.917 & 1.348 & 1.046 & - & 0.297 \\
\hline SE & 0.751 & 0.655 & 0.16 & 0.018 & - & 0.218 \\
\hline p-value & $<0.000$ & 0.001 & 0.019 & 0.044 & - & 0.008 \\
\hline
\end{tabular}


snow leopards in pastures were 0.961 times less likely to support snow leopard populations compared with those who actually did not see them in pastures.

Similar factors influenced the public's attitude toward wolves in the study sites. Teachers' attitudes were 1.917 times more positive toward wolves than those of people in other occupations. Increases in family landholding and number of earning family members resulted in 1.348 and 1.046 times more positive attitude to maintaining wolf populations. Furthermore, public attitudes in the Afghan Pamirs were more negative for wolves than the other two countries (Table 5).

\section{DISCUSSION}

This study depicts that predation induced livestock mortality (an average of 1.78 animals per household per year) constitutes one of the major threats to livestock and ultimately to the rural economy (an average of US\$191 per household per year) in the Pamir. However, the disease-caused livestock mortality, which is estimated at an average of 3.5 animals per household per year with a value of US\$352 overshadows the former. The latter is mostly not measured in studies aimed at understanding the dynamics of human-livestock-carnivore interaction. Available literature (Ostrowski 2007, Habib 2008, Dar et al. 2009, Li et al. 2013) supports this notion. The disease- and predation-induced economic impact varied across the study sites with the highest economic loss reported in the Afghan Pamirs, followed by the Pakistani and Tajik Pamirs. This reflects the remoteness of these areas and the lack of suitable social-ecological measures (Fitzherbert and Mishra 2003) to cope with the issue. The agropastoralist mountain communities of the Pamirs depend on livestock rearing (Schaller 1998) as a major source of livelihood and market/cull surplus animals for day-to-day monetary needs (Ostrowski 2007). In addition, livestock slaughter is a social obligation in the event of family deaths and weddings. Slaughtered animals are also offered to pirs or spiritual leaders (Mock et al. 2007). Our estimate of the revenues generated from annual livestock harvesting in the Pamirs is about US\$187,777 which translates into an average US\$1313 per household per year. These figures are crucial for assessments of the economic stresses facing mountain communities that live below the poverty line (Ehlers and Kreutzmann 2000, Hurni and Breu 2003) and loses of livestock due to predators and diseases further exacerbates the livelihood of the communities and builds hatred toward predators.

There were no reported instances of snow leopard predation on livestock in the Tajik Pamirs and all predation cases were related to wolves. This could be due to the limited data available from the area that forced us to run regression analysis by pooling data from all the three sites. Although, previous studies (Mishra and Fitzherbert 2003) have reported that wolves are a greater threat to livestock in the Pamirs as are snow leopards in the Hindu Kush. Brown bears and lynx did not feature in human-predator conflict in the three study sites. Previous studies in the Pamirs (Schaller 1998, Fitzherbert and Mishra 2003) also support these findings.

Our results were found to be in line with predator-focused studies from the Wakhan corridor and Pamirs. Wolves were responsible for the majority of livestock losses in the Tajik (100\%) and Afghan (70\%) Pamirs, while the snow leopard was found to be the major predator in the Pakistani Pamirs (65\%). Wolf predation has been a major issue in the Pamirs (Izumiyama et al. 2009) and has been controlled lethally by the locals by paying hunters to kill them (Watanabe et al. 2010).

Livestock predation by large carnivores has been reported to cause, on average, losses of 1-12 heads per household (Schaller et al. 1987, Oli et al. 1994, Mishra 1997, Hussain 2000, Jackson and Wangchuk 2001, Li et al. 2013) across Central and South Asia, and 1-2\% in the Wakhan Corridor (Ostrowski 2007, Habib 2008). Our study shows that the reported livestock mortality per household per year attributed to wolves and snow leopards was 0.6 in the Tajik Pamirs, 1.76 in the Pakistani Pamirs, and 2.8 in the Afghan Pamirs.

Predator persecution in response to attacks on livestock is a universal issue. Available literature (Hussain 2000, Mishra and Fitzherbert 2004, Watanabe et al. 2010) describes mass killing of both snow leopards and wolves in the Pamirs. The majority of respondents perceived wolves and snow leopards as lethal for livestock and consequently expressed desires to see reduced populations. The wolf was the least accepted carnivore in the Tajik and Afghan Pamirs while the snow leopard was less accepted in the Pakistani Pamirs. Factors affecting public attitudes toward large carnivores are understandable because livestock rearing and subsistence farming constitute the bulk of family revenues in the Pamirs; any threat to these limited means are not welcomed.

Overall literacy rates in these remote valleys are very low, but education is a crucial component of carnivore conservation; it plays a key role in equipping people with proconservation attitudes and practices. Educational programs aimed to gain public support for predators and their conservation is important in situations where economic compensation for livestock losses by predators is not feasible (Sillero-Zubiri and Laurenson 2001). For instance, informal education initiatives in Africa significantly reduced numbers of cheetahs removed by farmers per year (Marker et al. 2003). Other studies (e.g., Holmern et al. 2007) recommend both formal and informal education to increase public understanding and tolerance of predators. The educated people showed positive attitudes toward the large predators, as did the comparatively wealthy families (having comparatively larger landholding and more earning members in the family) toward high predation rates. Our findings suggest that poverty is one of the key factors linked with predator conservation in the Pamirs. Thus, the conservation of large carnivores in this part of the world requires tangible, incentive-based conservation measures to offset predator-induced economic losses and inculcate a sense of stewardship for carnivores.

\section{CONCLUSION}

This study adds to the limited available information on the dynamics of human-carnivore interaction in the Pamirs. An appreciation of the underlying factors is crucial for the long-term survival of both humans and carnivores. Moreover, this study shows that disease is a greater threat than predation to the mountain economy. We suggest using disease control as a conservation tool while initiating conservation management measures in the region. Various conservation organizations like the Snow Leopard Trust, Panthera, and SLF have already developed, and are implementing model programs in northern Pakistan that address disease-caused mortality of livestock. In return, communities agree to tolerate predation-induced livestock 
mortality and do not harm predators in their pastures. Livestock insurance schemes are another possibility if properly managed and expanded to all predators. However, such schemes can be difficult to implement because they are meant to compensate up to $20 \%$ of total loss (Hussain 2000, Simms et al. 2011) and are species specific. Considering poverty levels in the Afghan Pamirs, Fitzherbert and Mishra (2003) suggests launching Snow Leopard Enterprise, an incentive scheme initiated by the Snow Leopard Trust aimed at tackling human-snow leopard conflict in Mongolia and Pakistan.

Our results depict education as a catalyst in enhancing public tolerance for predators. We suggest bridging the incentive schemes with focused conservation education activities such as community learning sessions, establishment of school nature clubs for youth, and equipping them with the necessary resource material, as well as organizing other awareness raising events (Snow Leopard Network 2014).

Protected areas have proven to be safe refuges for carnivores besides developing carnivore-friendly public attitudes. Initiatives aimed at establishing a transboundary peace park in the Pamirs (Xie et al. 2007) will help reduce human-carnivore conflict by maintaining viable wild ungulate populations.

A recent study (Nowell et al. 2016) submits persecution of snow leopards due to predation on livestock as a major conservation concern and catalyst into the illegal trade across the range. Although, we did not notice any such incident during our study period, the rapid increase in human and livestock population and resulted encroachment to the large predators' habitat and habitat degradation are some of the indicators inducing predator persecution by the communities in the study sites. Detailed study to document the persecution of snow leopard and wolf and underlying considerations in the Pamir will help foster and fine tune the conservation measures.

The seclusion and inaccessibility of the Pamirs makes data collection a challenging task. The unavailability of large datasets could be considered a study shortcoming. More detailed studies are required to fully understand the complexities and dynamics of human-carnivore conflict, especially in the Tajik, Kirgiz, and Afghan Pamirs.

Responses to this article can be read online at: http://www.ecologyandsociety.org/issues/responses. $\mathrm{php} / 9348$

\footnotetext{
Acknowledgments:

We would like to thank the Parks and Wildlife Department, GilgitBaltistan (GB), the administration of Wakhan district, and Tajik Pamir for legal permissions, the Snow Leopard Network (SLN), University of Malaya (PPP Grant: PG002-2015B), Felidae Conservation Fund ( FCF), and Aga Khan Foundation ( $A K F$ ) for funding, AKF Badakhshan Regional Management, Dr. Najmuddin, and Mr. Romin Fararoon for support in the Afghan and Tajik Pamirs through natural resource management technical staff in the field, Mr. Azimsho Bakhronov, Dr. Mohiolam, Dr. Aslisho, and Dr. Shamsuddin for collecting information from the Afghan and Tajik
}

Pamirs during the field survey and investigation, and all survey participants. The Wildlife Conservation Network (WCN) provided scholarship for the PhD study of Jaffar Ud Din.

\section{LITERATURE CITED}

Anwar, M. B., R. Jackson, M. S. Nadeem, J. E. Janečka, S. Hussain, M. A. Beg, G. Muhammad, and M. Qayyum. 2011. Food habits of the snow leopard Panthera uncia (Schreber, 1775) in Baltistan, Northern Pakistan. European Journal of Wildlife Research 57:1077-1083. http://dx.doi.org/10.1007/s10344-011-0521-2

Bagchi, S., and C. Mishra. 2004. Living with large carnivores: snow leopard predation on livestock in the Spiti Trans-Himalaya. CERC Technical Report No. 11. Nature Conservation Foundation, Mysore, India and International Snow Leopard Trust, Seattle, Washington, USA.

Bangs, E., S. H. Fritts, J. A. Fontaine, D. W. Smith, K. M. Murphy, C. M. Mack, and C. C. Niemeyer. 1998. Status of gray wolf restoration in Montana, Idaho, and Wyoming. Wildlife Society Bulletin 26:785-798.

Berger, J., P. B. Stacey, L. Bellis, and M. P. Johnson. 2001. A mammalian predator-prey imbalance: grizzly bear and wolf extinction affect avian Neotropical migrants. Ecological Applications 11:947-960. http://dx.doi.org/10.1890/1051-0761 (2001)011[0947:AMPPIG]2.0.CO;2

Bliss, F. 2005. Social and economic change in the Pamirs (GornoBadakhshan, Tajikistan). Routledge, New York, New York, USA. http://dx.doi.org/10.4324/9780203405314

Chen, S. S., D. L. Donoho, and M. A. Saunders. 1998. Atomic decomposition by basis pursuit. SIAM Journal on Scientific Computing 20:33-61. http://dx.doi.org/10.1137/S1064827596304010

Dar, N. I., R. A. Minhas, Q. Zaman, and M. Linkie. 2009. Predicting the patterns, perceptions and causes of humancarnivore conflict in and around Machiara National Park, Pakistan. Biological Conservation 142:2076-2082. http://dx.doi. org/10.1016/j.biocon.2009.04.003

Din, J. U., S. Hameed, K. A. Shah, M. A. Khan, S. Khan, M. Ali, and M. A. Nawaz. 2013. Abundance of canids and human canid conflict in the Hindu Kush Mountain range of Pakistan. Wildlife Biology in Practice 9:20-29. http://dx.doi.org/10.2461/wbp.2013.9.5

Din, J. U., and M. A. Nawaz. 2010. Status of the Himalayan lynx in district Chitral, NWFP, Pakistan. Journal of Animal and Plant Sciences 20:17-22.

Ehlers, E., and H. Kreutzmann. 2000. High mountain ecology and economy potential and constraints. Pages 09-36 in E. Ehlers and H. Kereutzmann, editors. High mountain pastoralism in Northern Pakistan. Franz Steiner Verlag, Stuttgart, Germany.

Estes, J. A., M. T. Tinker, T. M. Williams, and D. F. Doak. 1998. Killer whale predation on sea otters linking oceanic and nearshore ecosystems. Science 282:473-476. http://dx.doi.org/10.1126/ science.282.5388.473

Fitzherbert, A., and C. Mishra. 2003. Afghanistan Wakhan mission technical report. United Nations Environment Programme and Food and Agriculture Organization, Rome, Italy. 
Fox, J. L., S. P. Sinha, R. S. Chundawat, and P. K. Das. 1991. Status of the snow leopard Panthera uncia in Northwest India. Biological Conservation 55:283-298. http://dx.doi.org/10.1016/0006-3207 (91)90033-6

Fox, J. L., and D. Tsering. 2005. Biodiversity conservation and natural resource exploitation on Tibets northwest Chang Tang highlands. Pages 49-57 in A. Boesi and F. Cardi, editors. Wildlife and plants in traditional and modern Tibet: conceptions, exploitation, and conversation. Memorie della Societa Italiana di Scienze Naturali, Milan, Italy.

Friedman, J. H., T. Hastie, and R. Tibshirani. 2010. Regularization paths for generalized linear models via coordinate descent. Journal of Statistical Software 33:1-22. http://dx.doi. org/10.18637/jss.v033.i01

Graham, K., A. P. Beckerman, and S. Thirgood. 2005. Humanpredator-prey conflicts: ecological correlates, prey losses and patterns of management. Biological Conservation 122:159-171. http://dx.doi.org/10.1016/j.biocon.2004.06.006

Habib, B. 2008. Status of mammals in Wakhan Afghanistan. Wildlife Conservation Society, Kabul, Afghanistan.

Holmern, T., J. Nyahongo, and E. Røskaft. 2007. Livestock loss caused by predators outside the Serengeti National Park, Tanzania. Biological Conservation 135:518-526. http://dx.doi. org/10.1016/j.biocon.2006.10.049

Hurni, H., and T. Breu. 2003. The Tajik Pamirs: challenges of sustainable development in an isolated mountain region. Center for Development and Environment (CDE), University of Berne, Berne, Switzerland.

Hussain, S. 2000. Protecting the snow leopard and enhancing farmers' livelihoods. Mountain Research and Development 20:226-231. http://dx.doi.org/10.1659/0276-4741(2000)020[0226: PTSLAE]2.0.CO;2

Hussain, S. 2003. The status of snow leopard in Pakistan and its conflict with local farmers. Oryx 37:26-33. http://dx.doi. org/10.1017/S0030605303000085

Izumiyama, S., M. Anarbaev, and T. Watanabe. 2009. Inhabitation of larger mammals in the Alai Valley of the Kyrgyz Republic. Geographical Journal 84:14-21. http://dx.doi. org/10.7886/hgs.84.14

Jackson, R., and R. Wangchuk. 2001. Linking snow leopard conservation and people-wildlife conflict resolution: grassroots measures to protect the endangered snow leopard from herder retribution. Endangered Species Update 18(4):138-141.

Karanth, K. U., and M. D. Madhusudan. 2002. Mitigating human-wildlife conflicts in southern Asia. Pages 250-264 in J. Terborgh, C. P. van Schaik, M. Roa, and L. C. Davenport, editors. Making parks work: identifying key factors to implementing parks in the tropics. Island Press, Covelo, California, USA.

Kreutzmann, H. 2003. Ethnic minorities and marginality in the Pamirian Knot: survival of Wakhi and Kirghiz in a harsh environment and global contexts. Geographical Journal 169:215-235. http://dx.doi.org/10.1111/1475-4959.00086
Li, J., H. Yin, D. Wang, Z. Jiagong, and Z. Lu. 2013. Humansnow leopard conflicts in the Sanjiangyuan Region of the Tibetan Plateau. Biological Conservation 166:118-123. http://dx.doi. org/10.1016/j.biocon.2013.06.024

Linkie, M., Y. Dinata, A. Nofrianto, and N. Leader-Williams. 2007. Patterns and perceptions of wildlife crop raiding in and around Kerinci Seblat National Park, Sumatra. Animal Conservation 10:127-135. http://dx.doi.org/10.1111/ j.1469-1795.2006.00083.x

Linnell, J. D. C., J. E. Swenson, and R. Andersen. 2000. Conservation of biodiversity in Scandinavian boreal forests: large carnivores as flagships, umbrellas, indicators, or keystones? Biodiversity \& Conservation 9:857-868. http://dx.doi.org/10.1023/ A:1008969104618

Löe, J., and E. Röskaft. 2004. Large carnivores and human safety: a review. AMBIO: A Journal of the Human Environment 33:283-288. http://dx.doi.org/10.1579/0044-7447-33.6.283

Mallon, D. P. 1984. The snow leopard in Ladakh. International Pedegree Book of Snow Leopards 4:23-37.

Marker, L. L., A. J. Dickman, M. G. L. Mills, and D. W. Macdonald. 2003. Aspects of the management of cheetahs, Acinonyx jubatus jubatus, trapped on Namibian farmlands. Biological Conservation 114:401-412. http://dx.doi.org/10.1016/ $\underline{\text { S0006-3207(03)00068-5 }}$

Mishra, C. 1997. Livestock depredation by large carnivores in the Indian trans-Himalaya: conflict perceptions and conservation prospects. Environmental Conservation 24:338-343. http://dx.doi. org/10.1017/S0376892997000441

Mishra, C., P. Allen, T. McCarthy, M. D. Madhusudan, A. Bayarjargal, and H. H. T. Prins. 2003. The role of incentive programs in conserving the snow leopards. Conservation Biology 17:1512-1520. http://dx.doi.org/10.1111/j.1523-1739.2003.00092. $\underline{\mathrm{X}}$

Mishra, C., and A. Fitzherbert. 2004. War and wildlife: a postconflict assessment of Afghanistan's Wakhan Corridor. Oryx 38:102-105. http://dx.doi.org/10.1017/S0030605304000158

Mock, J., K. O. Neil, and I. Ali. 2007. Socioeconomic \& range use survey of Wakhi households using the Afghan Pamir, Wakhan District, Badakhshan Province, Afghanistan. Wildlife Conservation Society, Kabul, Afghanistan.

Namgail, T., J. L. Fox, and Y. V. Bhatnagar. 2007. Carnivorecaused livestock mortality in Trans-Himalaya. Environmental Management 39:490-496. http://dx.doi.org/10.1007/s00267-005-0178-2

Naughton-Treves, L. 1998. Predicting patterns of crop damage by wildlife around Kibale National Park, Uganda. Conservation Biology 12:156-168. http://dx.doi.org/10.1111/j.1523-1739.1998.96346. $\underline{\mathrm{X}}$

Nowell, K., and P. Jackson. 1996. Wild cats. Status survey and conservation action plan. International Union for Conservation of Nature, Gland, Switzerland.

Nowell, K., J. Li, M. Paltsyn, and R. K. Sharma. 2016. An ounce of prevention: snow leopard crime revisited. TRAFFIC, Cambridge, UK. 
Oli, M. K., I. R. Taylor, and M. E. Rogers. 1994. Snow leopard Panthera uncia predation of livestock: an assessment of local perceptions in the Annapurna Conservation Area, Nepal. Biological Conservation 68:63-68. http://dx.doi.org/10.1016/0006-3207 (94)90547-9

Olson, D. M., E. Dinerstein, E. D. Wikramanayake, N. D. Burgess, G. V. N. Powell, E. C. Underwood, J. A. D'amico, I. Itoua, H. E. Strand, J. C. Morrison, C. J. Loucks, T. F. Allnutt, T. H. Ricketts, Y. Kura, J. F. Lamoreux, W. W. Wettengel, P. Hedao, and K. R. Kassem. 2001. Terrestrial ecoregions of the world: a new map of life on Earth: a new global map of terrestrial ecoregions provides an innovative tool for conserving biodiversity. BioScience 51:933-938. http://dx.doi.org/10.1641/0006-3568(2001)051[0933: TEOTWA]2.0.CO;2

Ostrowski, S. 2007. Wakhi livestock in Bbig Pamir in 2006. Afghanistan Ecosystem Health Project. Wildlife Conservation Society, New York, New York, USA.

Pratt, D. G., D. C. Macmillan, and I. J. Gordon. 2004. Local community attitudes to wildlife utilisation in the changing economic and social context of Mongolia. Biodiversity \& Conservation 13:591-613. http://dx.doi.org/10.1023/b:

bioc. $0000009492.56373 . c c$

R Development Core Team. 2015. R: A language and environment for statistical computing. R Foundation for Statistical Computing, Vienna, Austria.

Rosen, T., S. Hussain, G. Mohammad, R. Jackson, J. E. Janecka, and S. Michel. 2012. Reconciling sustainable development of mountain communities with large carnivore conservation. Mountain Research and Development 32:286-293. http://dx.doi. org/10.1659/MRD-JOURNAL-D-12-00008.1

Røskaft, E., B. Händel, T. Bjerke, and B. P. Kaltenborn. 2007. Human attitudes towards large carnivores in Norway. Wildlife Biology 13:172-185. http://dx.doi.org/10.2981/0909-6396(2007) 13[172:HATLCI]2.0.CO;2

Schaller, G. B. 1976. The Serengeti lion: a study of predator-prey relations. University of Chicago Press, Chicago, Illinois, USA. http://dx.doi.org/10.7208/chicago/9780226736600.001.0001

Schaller, G. B. 1998. Wildlife of the Tibetan Steppe. University of Chicago Press, Chicago, Illinois, USA.

Schaller, G. B., L. Hong, Talipu, L. Hua, R. Junrang, Q. Mingjiang, and W. Haibin. 1987. Status of large mammals in the Taxkorgan Reserve, Xinjiang, China. Biological Conservation 42:53-71. http://dx.doi.org/10.1016/0006-3207(87)90052-8

Sillero-Zubiri, C., and M. K. Laurensen. 2001. Interactions between carnivores and local communities: conflict or coexistence? Pages 282-312 in J. Gittleman, K. Funk, D. Macdonald, R. Wayne, editors. Carnivore Conservation, Conservation Biology Series 5. Cambridge University Press, Cambridge, UK.

Simms, A., Z. Moheb, Salahudin, H. Ali, I. Ali, and T. Wood. 2011. Saving threatened species in Afghanistan: snow leopards in the Wakhan Corridor. International Journal of Environmental Studies 68:299-312. http://dx.doi.org/10.1080/00207233.2011.577147

Snow Leopard Network. 2014. Snow Leopard survival strategy. Snow Leopard Network, Seattle, Washington, USA.
Terborgh, J., L. Lopez, P. Nuñez, M. Rao, G. Shahabuddin, G. Orihuela, M. Riveros, R. Ascanio, G. H. Adler, T. D. Lambert, and L. Balbas. 2001. Ecological meltdown in predator-free forest fragments. Science 294:1923-1926. http://dx.doi.org/10.1126/ science. 1064397

Thirgood, S., S. Redpath, I. Newton, and P. Hudson. 2000. Raptors and Red Grouse: conservation conflicts and management solutions. Conservation Biology 14:95-104. http:// dx.doi.org/10.1046/j.1523-1739.2000.99013.x

Tibshirani, R. 1996. Regression shrinkage and selection via the lasso. Journal of the Royal Statistical Society 58:267-288.

Tong, X., X. He, L. Sun, and J. Sun. 2009. Variable selection for panel count data via non-concave penalized estimating function. Scandinavian Journal of Statistics 36:620-635. http://dx.doi. org/10.1111/j.1467-9469.2009.00658.x

Treves, A., and K. U. Karanth. 2003. Human-carnivore conflict and perspectives on carnivore management worldwide. Conservation Biology 17:1491-1499. http://dx.doi.org/10.1111/ j.1523-1739.2003.00059.x

Tsering, D., J. Farrington, and K. Norbu. 2006. Human-wildlife conflict in the Chang Tang Region of Tibet: the impact of Tibetan brown bears and other wildlife on nomadic herders. WWF-China, Tibet.

Watanabe, T., S. Izumiyama, L. Gaunavinaka, and M. Anarbaev. 2010. Wolf depredation on livestock in the Pamir. Geographical Studies 85:26-36. http://dx.doi.org/10.7886/hgs.85.26

Wechselberger, M., and D. Leizinger. 2005. Die akseptanz von bär, wolf und luchs in Österreich. WWF, Vienna, Austria.

Woodroffe, R. 2000. Predators and people: using human densities to interpret declines of large carnivores. Animal Conservation 3:165-173. http://dx.doi.org/10.1111/j.1469-1795.2000.tb00241. $\underline{\mathrm{X}}$

Xie, Y., A. Kang, J. Wingard, and P. Zahler. 2007. The Pamirs Tran-boundary protected area. A report on the 2006 International Workshop on Wildlife and Habitat Conservation in Pamirs. Wildlife Conservation Society, New York, New York, USA. 
Appendix 1: Human-carnivore interaction survey, questionnaire

Enumerator Name Date

Respondent Name Village Name

Education Age

Ethnic background Occupation

How many earning members are there in the household? $\mathrm{HH}$ size

Home much agricultural land your family own?

Predators Status:

Did you sight any of following species in past five years?

\begin{tabular}{c|c|c|c|c|c|c}
\hline & $\begin{array}{c}\text { Snow } \\
\text { Leopard }\end{array}$ & $\begin{array}{c}\text { Common } \\
\text { Leopard }\end{array}$ & Wolf & Lynx & Brown bear & Black bear \\
\hline Numbers & & & & & & \\
\hline $\begin{array}{c}\text { Status } \\
\text { (Common/Rare/Absent }\end{array}$ & & & & & & \\
\hline
\end{tabular}

Population of which species you wish to increase/maintain/reduce /eliminate from your area:

\begin{tabular}{c|c|c|c|c|c|c}
\hline & Snow Leopard & Common Leopard & Wolf & Lynx & Brown bear & Black bear \\
\hline$\uparrow / \rightarrow / \downarrow / \mathrm{x}$ & & & & & & \\
\hline
\end{tabular}

Which one is most dangerous for livestock, rate 1-4 (from high to low):

\begin{tabular}{|c|c|c|c|c|c|}
\hline Snow Leopard & Common Leopard & Wolf & Lynx & Brown bear & Black bear \\
\hline & & & & & \\
\hline
\end{tabular}

Livestock:

How many livestock your family own?

\begin{tabular}{l|l|l|l|l|l}
\hline Livestock & Goats & Sheep & Cattle & Yak & Equine \\
\hline Number & & & & & \\
\hline Vaccinated & & & & & \\
\hline
\end{tabular}

Livestock sold in 1 year:

\begin{tabular}{l|l|l|l|l|l}
\hline Livestock & Goats & Sheep & Cattle & Yak & Equine \\
\hline Number & & & & & \\
\hline Total Income in Rs & & & & & \\
\hline Slaughtered & & & & & \\
\hline
\end{tabular}

Mortality due to Disease in 5 years:

\begin{tabular}{l|l|l|l|l|l}
\hline Livestock & Goats & Sheep & Cattle & Yak & Equine \\
\hline Number & & & & & \\
\hline
\end{tabular}

Which livestock grazing system do you follow?

Daily $\square$; $\quad$ By turn $\square$; $\quad$ Shepherd $\square$; 
Predation in 5 years:

\begin{tabular}{l|l|l|l|l|l}
\hline & Goats & Sheep & Cattle & Yak & Equine \\
\hline Snow Leopard & & & & & \\
\hline Common Leopard & & & & & \\
\hline Lynx & & & & & \\
\hline Wolf & & & & & \\
\hline Brown Bear & & & & & \\
\hline Black Bear & & & & & \\
\hline
\end{tabular}

Details of Predation:

\begin{tabular}{|c|c|c|c|c|c|c|}
\hline Predator & Month, year & Location & Prey type, no. & Prey sex & Prey Age & Time \\
\hline & & & & & & \\
\hline & & & & & & \\
\hline & & & & & & \\
\hline & & & & & & \\
\hline & & & & & & \\
\hline & & & & & & \\
\hline & & & & & & \\
\hline & & & & & & \\
\hline
\end{tabular}

Crop damage by wildlife in past 1 year (estimated economic loss):

\begin{tabular}{l|l|l|l|l}
\hline Species & Winter & Spring & Summer & Autumn \\
\hline Brown Bear & & & & \\
\hline Black Bear & & & & \\
\hline Other (name) & & & & \\
\hline
\end{tabular}

Status of Ungulates:

\begin{tabular}{c|l|l|l|l}
\hline Species & Himalayan Ibex & Blue sheep & Marco Polo Sheep & Markhor \\
\hline Number & & & & \\
\hline $\begin{array}{c}\text { Status } \\
\text { Common/Rare/Absent }\end{array}$ & & & & \\
\hline
\end{tabular}

Suggested conservation measures:

For carnivores:

For Ungulates: 